\title{
Acerca de la metafísica
}

\author{
About metaphysics \\ Dante Dávila Morey \\ Universidad Nacional Mayor de San Marcos, Lima, Perú \\ Pontificia Universidad Católica del Perú, Lima, Perú \\ Contacto: ddavilam@unmsm.edu.pe \\ http://orcid.org/0000-0001-8062-6537
}

\begin{abstract}
Resumen
En nuestra época, la metafísica se ha convertido en un estudio de dudosa naturaleza hasta el punto de que se la ha pretendido eliminar de la filosofía. Pero ¿de qué hablamos cuando nos referimos a la metafísica? ¿Qué ha sido y qué es como para que haya experimentado tan extraño destino? En lo que sigue se discutirán tres tesis al respecto: la primera, la metafísica es sus problemas; la segunda, la metafísica es su historia; y la tercera, la metafísica es sus posibilidades. Palabras clave: Filosofía, metafísica, historia de la filosofía, historia de la metafísica.
\end{abstract}

\begin{abstract}
In our times, metaphysics has become a study of dubious nature to such an extent that it has been tried to be eliminated from philosophy. But what are we talking about when we refer to metaphysics? What it has been like and what it is for having experienced such a strange destiny? In the following, three theses will be discussed: the first, metaphysics is its problems; the second, metaphysics is its history; and the third, metaphysics is its possibilities.
\end{abstract} Keywords: Philosophy, metaphysics, history of philosophy, history of metaphysics.

Aceptado: 13.10 .17

En nuestra época, la metafisica se ha convertido en un estudio de dudosa naturaleza, hasta el punto de que se la ha pretendido eliminar de la filosofía. Así, el adjetivo metafísica se ha transformado en un calificativo con el que se refiere casi siempre peyorativamente a lo abstracto e innecesariamente difícil, o para indicar casi siempre condenatoriamente a lo irreal, poco práctico e inservible (Albizu, 1989). De haber sido considerada durante siglos como las raíces del árbol del conocimiento, se ha pretendido que ya no ocupe siquiera el lugar de las ramas más humildes, sino que simplemente no tenga lugar en el árbol y se la extirpe completamente de él. Pero, aun así, la metafísica se resiste a desaparecer y hasta se ha dicho que en los 
últimos tiempos ha experimentado un silencioso y lento renacimiento. Pero ¿de qué hablamos cuando nos referimos a la metafísica? ¿Qué ha sido y qué es como para que haya experimentado tan extraño destino? En lo que sigue se discutirán tres tesis al respecto: la primera, la metafísica es sus problemas; la segunda, la metafísica es su historia; y la tercera, la metafísica es sus posibilidades.

\section{La metafísica es sus temas}

La metafísica ha adquirido la forma de los problemas que se ha planteado. La primera forma que adopta es la del estudio de los principios incondicionados que rigen y explican la totalidad real. Si se considera que el ser es el principio más alto, entonces ella se convierte en el estudio del problema del ser en tanto ser, ello es, el esclarecimiento del ser en sentido universal y no en el de las determinaciones particulares de las ciencias. Estamos ante el problema de lo que significa ser, lo que significa existir. Ahora bien, si se considera que su campo es más amplio y que no se refiere a un único principio, entonces ella asume una segunda forma, la del estudio del problema de las causas primeras y los principios fundacionales que rigen la realidad, como son el ser y sus sentidos, la unidad y los opuestos, el principio de no contradicción, el principio de identidad y el de tercio excluido. Una variante de esta segunda forma sería aquella que la considera como el estudio de las explicaciones últimas, de los elementos que componen la realidad, desde los cuales proviene y hacia los cuales habría que remontarse para poderla explicar. Ahora bien, si se considera que nuestro acceso al mundo es a partir de apariencias, las cuales nos presentan las cosas como múltiples y cambiantes, pero que ni la multiplicidad ni el cambio dan razón suficiente de la realidad, entonces la metafísica asume una tercera forma, la del estudio del problema de las esencias que están detrás de las apariencias. Las esencias están en la base de nuestra comprensión de las cosas, pero no se identifican con ellas; son unidades inmutables que forman una estructura inteligible, ajena al espacio, al tiempo y al cambio, y por ello solo pueden ser captadas por nuestro intelecto. Y si tomamos en cuenta que para explicar la realidad no es suficiente con asumir que hay cosas en el mundo, sino que es preciso indagar qué aspectos de él no pueden ser de otra manera y se cumplen en todo mundo posible, o qué aspectos de él podrían ser de 
otra manera, entonces la metafísica asume una cuarta forma, la del estudio del problema de la necesidad y de las posibilidades básicas que explican las cosas. Pues bien, en estas diversas formas que adopta la metafísica se han ido delineando sus problemas y temas más precisos, desde los más tradicionales como son los de la naturaleza del alma, el origen del mundo y la existencia de Dios; pasando por el problema por antonomasia, el problema del ser, hasta llegar a otros vinculados con ellos como son los problemas del tiempo, los universales, el determinismo y el libre albedrío o la identidad personal (Conee y Sider, 2013).

Ciertamente, la metafísica es un conjunto de problemas. Pero, enunciada de esta manera y sin hacer las distinciones pertinentes, esta tesis conduce a muchas dificultades; así, muchos de tales problemas se han mostrado como insuficientemente planteados, ya porque pretendían ir más allá de nuestras facultades cognoscitivas o nuestras capacidades lingüísticas, ya porque cosificaban las realidades de las que pretendían dar cuenta, $y$, en este sentido, tales problemas han perdido vigencia o se han vuelto irrelevantes, si es que no han sido disueltos. Pero, de este hecho no se deduce que los temas metafísicos deban ser rechazados del todo, puesto que ellos pueden reaparecer en otro ámbito y bajo distintas formas. En efecto, la metafísica — tal como nos enseña Kant— es como un árbol del cual se pueden cortar las ramas, mas no extirpar su raíz ${ }^{1}$. Ella no es sólo un conocimiento que ha tenido pretensiones de convertirse en una ciencia legítima, sino que es al mismo tiempo una actitud enraizada en el espíritu humano. En tal sentido, es una tendencia del hombre que lo conduce a plantearse problemas que lo inquietan como aguijones y lo cuestionan en lo más vivo de su existencia; indagaciones que renovadamente nos habitan y que van desde la pregunta por el sentido de la vida humana, el sentido del dolor y de la muerte, hasta preguntas por el significado de la realidad y nuestro acceso a ella, la pregunta por lo que es y por qué es así, la pregunta de por qué hay cosas y no más bien nada, la naturaleza del tiempo, Dios, entre otros. La manera como se han planteado tradicionalmente los problemas de la metafísica constituye una forma de su despliegue, pero no el único. Desde este punto de vista, la metafísica es el horizonte espiritual del que no podemos salir y en el que todo ser humano está ubicado por el solo hecho de existir, y es la dis- 
tancia inevitable que debemos tomar respecto de la experiencia si queremos comprenderla (Grondin, 2011, p. 379). Por tanto, los problemas de la metafísica entendida como una pretensión de ser ciencia pueden haber sido cuestionados, pero no las indagaciones e inquietudes que brotan del alcance metafísico del espíritu humano. Y es la indagación de este suelo espiritual en el que estamos enraizados lo que ha constituido y constituye el punto de partida para una rehabilitación de la indagación metafísica. Por consiguiente, la metafísica, lejos de haber perdido vigencia, es un imperativo urgente de la condición humana.

Sin embargo, por otro lado, se ha argumentado que la metafísica - concebida ya no desde sus problemas, sino desde la historia del pensamiento- - ha experimentado un derrumbe incuestionable y ha agotado sus posibilidades. Indaguemos si esta afirmación es consistente.

\section{La metafísica es su historia}

Para la conciencia filosófica contemporánea, lo más evidente es que los problemas de la metafísica tienen una historicidad, que ha quedado registrada en una tradición que surgió con los griegos y ha llegado hasta nosotros. Historia de diálogo y de críticas virulentas; historia de olvidos explicables y de reconsideraciones inesperadas. Esta historia tiene algunos momentos fundamentales. Parménides postuló la oposición más alta posible entre el ser y el no ser, entre la necesidad de que el ser sea y de que el no ser no sea; el ser es lo único decible y pensable, y desde él las apariencias son relativizadas o mostradas como contradictorias. Los filósofos inmediatamente posteriores asumieron el problema de recuperar los fenómenos que habían quedado rechazados, por lo que, en tal sentido, se podría decir que la filosofía posterior es una respuesta al desafío planteado por Parménides. Dicha recuperación se encuentra en Platón, en la doctrina de las Ideas: las cosas se explican desde las ideas, unidades eternas e inmóviles que, a su vez, se explican desde la idea del bien, unidad suprema que está más allá de la esencia. Y en Aristóteles, en el horizonte de la filosofía primera, y, más precisamente, en el estudio de los distintos sentidos de ser referidos a la unidad de la sustancia ${ }^{2}$. Pero la metafísica de la Antigüedad llega a su consumación en la filosofía de Plotino: 
el Uno es principio supremo; todo proviene de él y va hacia él. La metafísica medieval buscó esclarecer el sentido de la creación del mundo hecha por Dios, pero al realizar tal búsqueda con la ayuda de los conceptos de la Antigüedad se movió dentro del ámbito especulativo abierto por ella. Es con los filósofos modernos con quienes surge una nueva actitud. Se critica la tradición por haber fundado el saber en criterios exteriores a la pureza de la razón, y se postula una metafísica de la subjetividad que busca esclarecer los principios de la realidad a partir de la verdad incontrovertible del sujeto: Descartes establece una metafísica según la verdad clara y distinta de cogito; Spinoza, una metafísica ética según el modo de la geometría; y Leibniz, una metafísica de formas sustanciales. Pero es con Kant con quien la metafísica se convierte en problema, pues la razón al establecerse como autoconciencia que busca discernir su propia naturaleza y el alcance de sus límites, se pregunta radicalmente por la posibilidad de la metafísica como ciencia y por su realidad como disposición natural. Si bien Kant critica la metafísica tradicional y postula una metafísica de la libertad, es con él con quien nos preguntamos radicalmente por el futuro de la metafísica, por la naturaleza de sus objetos, la validez de sus métodos y la legitimidad de sus pretensiones. Los idealistas alemanes rechazan la metafísica de la cosa en sí que, según ellos, todavía quedaba como rezago en la filosofía kantiana, y orientan la especulación metafísica por una dirección que logre superar los dualismos de la modernidad y establezca la buscada identidad entre pensar y ser: Fichte postula una metafísica del Yo, Schelling una metafísica de la identidad y Hegel una metafísica del espíritu. Con ellos, la metafísica cumple sus pretensiones de ser un saber absoluto, un conocimiento de la totalidad real desde la mirada de Dios; desarrolla sus posibilidades plenas y llega a su culminación. Pero esta culminación significa un olvido de la singularidad de los individuos, de las condiciones históricas y concretas en que viven. Por ello, la metafísica experimenta su derrumbe. Y este derrumbe se realiza en las críticas radicales de Marx, Kierkegaard y Nietzsche, por un lado, y en las críticas del positivismo decimonónico, por el otro. Ya más recientemente, la metafísica sufrió los ataques de dos vertientes representativas — entre otras - del pensamiento: los herederos del marxismo y la filosofía analítica. Los primeros 
la consideraron como una teología disfrazada, un pensamiento originado por la alienación del género humano; y los segundos — sobre todo los cultores de la primera época de la filosofía analítica- como un conjunto de proposiciones sin sentido frente a las cuales, en el mejor de los casos, lo mejor sería guardar silencio. Así, la historia de la metafísica se nos presenta como un campo de batalla de inacabables disputas, hechas con las armas de la argumentación y el heroísmo de los conceptos. Y de su agonía.

No obstante, la metafísica se rehúsa a morir. En el último siglo ha experimentado una rehabilitación, no gracias a sus eternos defensores de escuelas filosóficas de raigambre teológica que postulan una metafísica dogmática o una filosofía perenne, sino por obra del poderoso pensamiento de Heidegger. Desde el comienzo de su producción filosófica, Heidegger nos muestra la necesidad de recuperar la pregunta por el ser: en Ser y tiempo (1927) trata de la pregunta por el sentido del ser, y en su obra posterior, paradigmáticamente en Contribuciones a la filosofía (1936), de la verdad del ser. En Ser y tiempo, la metafísica asume la tarea de una interrogación radical sobre la cuestión del ser, que se apropia de su objeto a la luz de una destrucción de la historia de la ontología ${ }^{3}$ y en ¿Qué es metafisica? (1929) aparece como el acontecimiento por excelencia de nuestro ser. Posteriormente, Heidegger postuló la constitución onto-teo-lógica de la metafísica, la necesidad de superar la metafísica reiterándola, y su consumación en nuestra civilización nihilista, planetaria y técnica. A partir de Heidegger, y con diversas formas, ha habido distintas líneas de recuperación y desarrollo de la metafísica (Grondin, 2011): por un lado, por ejemplo, con Sartre y Merleau-Ponty se podría hablar de una metafísica de la existencia; con Gadamer, de una dimensión metafísica del lenguaje; y con Levinas, de la recuperación metafísica de la trascendencia. Pero, por otro, en el mundo angloparlante, cada vez hay un interés creciente por los temas metafísicos, muchos de los cuales han encontrado un rigor renovado y una claridad admirable a partir de lo más logrado de esta importante tradición (Garrett, 2010). Ahora bien, si la metafísica no solo es un conocimiento que se ha desplegado durante siglos, sino también una disposición natural del hombre, entonces, aparte de la historia ininterrumpida que llega documentada 
desde los griegos hasta nosotros, ella tiene paralelamente otra historia: la historia que se gesta en nuestra disposición natural hacia ella, la historia silenciosa que se desarrolla en el alma inquieta. Esta historia se despliega en la individualidad de nuestro espíritu que asume radicalmente su negatividad (siguiendo a Hegel), se gesta como acontecimiento que individualiza nuestra existencia y me cuestiona en primera persona (siguiendo a Heidegger), o simplemente (siguiendo a Gramsci) aparece como una "filosofía espontánea", presente en el lenguaje mismo, en el sentido común, en la religión popular y por consiguiente en lo que se llama el folklore (Gramsci, 1970, p. 6). En tal sentido, sería preciso hacer una fenomenología del espíritu metafísico, que dé cuenta de esta historia silenciosa. Por tanto, la metafísica, desde el punto de vista de la historia del pensamiento, no solo no ha muerto ni está en una supuesta agonía, sino que ha experimentado una revitalización. Y ello no solamente por una dinámica propia de su tradición, sino también - y sobre todo- porque la metafísica y su propia tradición se enraízan en la disposición natural del hombre hacia ella, en esta historia del espíritu individual que conlleva una constante renovación de las interrogaciones que se gestan en lo más profundo del ser humano.

Hasta aquí hemos explicado en qué sentido se podría decir que la metafísica es sus problemas y en qué sentido es su historia. Pero, ella es también sus posibilidades.

\section{La metafísica es sus posibilidades}

La metafísica es una tradición de problemas e indagaciones. La forma $-o$ las formas - que ha adoptado no ha sido la única ni lo será. Ella es también un conjunto de posibilidades que pueden ser desplegadas y cumplidas. Podemos, por ejemplo, volver a los mismos problemas desde otras preguntas, para poner a prueba la plausibilidad y la consistencia de los planteamientos. Podemos también plantear nuevos problemas o nuevas preguntas, que han ido surgiendo al asumir la complejidad de nuestra situación. Pero también podemos volver a considerar problemas que no fueron suficientemente desarrollados o cayeron inesperadamente en el olvido, pero que experimentamos como interpelaciones relevantes para nosotros. Si la metafísica es como una planta enraizada en nuestro espíritu, 
es posible cultivarla, abonarla cuidadosamente, regarla con esmero, suministrarle la luz necesaria, es decir, es posible desarrollarla. Siguiendo esta línea, en lo que sigue se esbozará una metafísica de la nada.

En nuestra vida establecemos relaciones con las cosas, con otras personas y con nosotros mismos. Cuando producimos algo, deseamos que el objeto producido por nuestro trabajo sea eficiente y cumpla su función. Nuestras actividades no solo las realizamos, sino que deseamos realizarlas bien: no solo queremos comer, sino gozar de una buena comida, ni solo queremos dormir, sino gozar de un buen descanso. Por otra parte, nos relacionamos con otras personas en la casa o en el trabajo, en el estudio o en la recreación, pero desearíamos que tales vínculos, lejos de ser tortuosos o indiferentes, fuesen gratificantes para nuestras vidas, y desearíamos que en vez de hacernos sentir extraños en el mundo nos hicieran sentir acogidos y seguros. Finalmente, cuando nos relacionamos con nosotros mismos, cada uno de nosotros, en primera persona, no solo quisiera vivir en un sentido puramente biológico, cumpliendo las funciones básicas que le permitan existir, sino que desearía vivir bien, desearía que la vida no fuese solo un alejamiento del dolor y un olvido de la muerte, sino experimentada como el gozo de vivir. Nuestra vida entera está sostenida por el deseo. Ahora bien — como enseñan los griegos - en la estructura del deseo se revela una relación de carencia y posesión: hay carencia porque deseo algo que me falta y busco completar esta ausencia; y hay posesión porque sé lo que me falta y este saber es una presencia que guía mi búsqueda. El deseo tiene la estructura de una ausencia y una presencia. Esa ausencia, lo que falta, eso que no poseo, es un no ser. Pero la presencia, lo que poseo, está incompleta y, por tanto, también está estructurada sobre la base de un no ser. Por ello, el no ser no actuaría como una causa final que mueve atrayendo, ni como una causa eficiente que mueve impulsando, pues en ambos casos se trataría de un no ser exterior que actuaría de acuerdo con el principio de causalidad (Lyotard, 2012, pp. 81-82). Pero el deseo no puede tener una estructura causal, sino que más bien está sostenido por una dialéctica de presencia y ausencia: presencia del no ser bajo la forma de una ausencia, ausencia de un ser bajo la forma de una presencia. El no ser está tanto en lo que me falta como en lo que poseo. Entonces, 
se trata de un no ser interior que escinde la existencia y la nihiliza (Sartre, 2005), de tal modo que vivir no consistiría en una búsqueda por permanecer en el ser, sino en una fuerza que siempre nos expone al no ser. Y esta exposición al no ser es una alteridad, es un movimiento que siempre va hacia lo otro. Pero no hacia un otro exterior, sino hacia una alteridad interior, hacia lo otro presente en uno mismo como ausencia. Ahora bien, si la vida está animada por el deseo y, a su vez, el deseo está regido por el no ser, ¿cómo entender el no ser?

En el Poema de Parménides está formulada la tesis por la que se ha desplegado la metafísica occidental. Así, en B2.1-6 la Diosa señala:

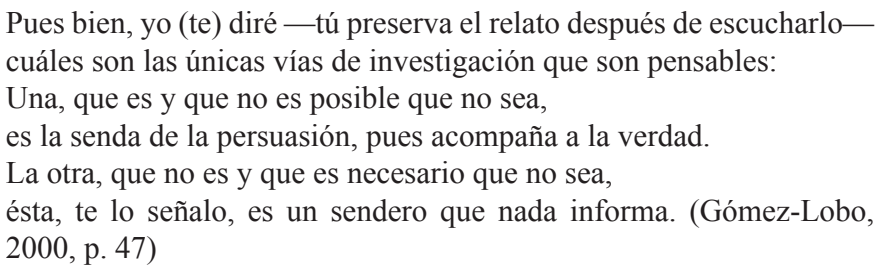

Lo que en este pasaje se formula es la oposición suprema entre ser y no ser; más precisamente, entre la necesidad de que el ser sea y la necesidad de que el no ser no sea. Y podríamos decir, más radicalmente, se postula la necesidad de la oposición entre, por un lado, la necesidad de que el ser sea y, por otro, la necesidad de que el no ser no sea. Por tanto, la necesidad de que el ser sea es al mismo tiempo la necesidad de que el no ser no sea. Pero como la vía del no ser es inviable y nada informa, debe ser abandonada, y solo nos queda la vía del ser. Desde entonces, la metafísica se ha entendido como una meditación acerca del ser. Mas ¿qué sucede con el no ser? Nos dice Parménides que la vía del ser acompaña a la verdad; por ello, hay una estrecha relación entre ser y verdad. Ahora bien, si la verdad es a-létheia, no-ocultamiento, des-ocultamiento, entonces el ocultamiento (léthe) es la retracción necesaria que hace posible la mostración del ser. El ocultamiento no es un suceso contingente o arbitrario, sino una necesidad para que el ser se muestre, es decir, el ser se muestra porque necesariamente el no ser se retrae. Si la verdad es des-ocultamiento, entonces el ocultamiento es retracción, es no-ser. Por ello, la verdad como a-létheia, la verdad como des-ocultamiento es 
no-no-ser. El fenómeno de la verdad lleva en su raíz misma una doble negación. Y como la verdad acompaña al ser, el ser es no-no-ser. Esto significa que no es suficiente que el ser sea concebido como negación del no-ser, sino que sea el no ser el que haga posible el ser. Es preciso pensar el no ser, no como lo opuesto del ser, sino como el suelo del que emergen tanto el ser como el no-ser. Este suelo originario es la nada.

La metafísica sería una meditación acerca de la nada. Pero no estaríamos ante un nuevo problema o una nueva figura histórica que ella habría adoptado. La nada se retrae, se rehúsa a salir a la luz y nihilizándose de esta manera es condición necesaria de toda manifestación posible. Ahora bien, apuntando a esta nihilización que impera en toda presencia y luchando contra ella es como las cosas buscan ser-algo y mantenerse en su ser, pero tal aspiración termina siempre en constitución diferida; apuntando a esta nihilización y en tensión con ella es como todo proyecto metafísico busca constituirse, mas siempre termina fracturado y condenado a su propio desfondamiento. La nada no es una cosa, un objeto, una sustancia o una determinación, sino lo anterior a toda posible determinación. Pero aquí habría que entender esta anterioridad como la nihilización originaria que impide toda constitución. Quizás por este carácter nihilizador es que la nada siempre ha sido pasada por alto como si fuera una mera nada, una ausencia, un defecto, una mera carencia, cuando en realidad es la potencia de su retracción la que le da su dignidad. En efecto, es la mudez de su retracción la que hace posible la elocuencia del ser. La metafísica es, pues, la gloriosa gesta de la nada, y solo apuntando a ella es como se hará justicia a la realidad que se oculta mostrándose. Por ello, podríamos decir que la metafísica ha sido el olvido de la nada y su confusión con una mera ausencia o una mera indeterminación. Asumiendo este olvido nihilizador y volviendo siempre a él es como ella asumiría sus posibilidades. Es preciso mostrar que en toda experiencia humana, en toda actividad, en toda praxis y valoración hay un fondo de nihilización y acontece la nada como retracción que le da su peso a la realidad. Desde este punto de vista, la historia de la metafísica tiene un suelo nihilista, del cual se alimenta y por el cual persiste, y habría que tomar en cuenta los momentos fundamentales de esta gesta de la 
nada. Un primer momento estaría en la sexta hipótesis del Parménides de Platón, que señala que si lo uno no es, no existe en ningún sentido y, por tanto, no habría determinación posible. Se trataría del no ser absoluto del uno que destruiría su propia identidad (Platón, 2015). Un segundo momento sería el pensamiento de Maestro Eckhart. Él nos enseña que para acceder a la sabiduría hay que vaciar el alma de todo contenido, propiedad o atributo, desasirse de todo para permitir la entrada del Verbo en nosotros. En tal sentido, la sabiduría es el fruto de la nada y solo puede fecundar a partir de la experiencia de ella (Maestro Eckhart, 2011). Un tercer momento estaría en Hegel. En la Ciencia de la lógica, señala que las abstracciones más altas, carentes de determinaciones, son el ser y la nada desde las cuales, y participando de ambas, surge el devenir (Hegel, 2011). Ahora bien, la primera determinación es la existencia (Da-sein), el algo determinado, es decir, se toma la vía del ser. Pero si el ser y la nada son los principios más altos, ¿por qué optar por el camino del ser y no por el de la nada? Habría que desplegar el otro camino, el camino de la nada, sin que esta pierda su potencia nihilizadora, y donde la primera tarea consistiría en interpretar su primera determinación, la nada determinada (Da-nichts). El cuarto momento sería el pensamiento de Heidegger y tendría como capital punto de partida el $\S 58$ de Ser y tiempo, donde se señala que el cuidado, en cuanto proyecto arrojado, tiene el carácter de una nihilidad existencial.

Es preciso seguir pensando este fondo nihilizador como una posibilidad de la experiencia metafísica. Pero pensar tomando en cuenta la situación en la que estamos ubicados y desde la que vivimos esta experiencia. Y ello significa, entre otras cosas, pensar con nuestras lenguas y en nuestras lenguas. Pues así como Maestro Eckhart - al igual que Raimundo Lulio y Dante - pensaba que, frente al latín, la lengua llamada vulgar era lenguaje interior, así también nosotros podríamos pensar que frente a las lenguas que se han pretendido metafísicas, para nosotros el castellano, el quechua y el aimara son las lenguas de nuestra interioridad.

\section{Agradecimientos}

Una versión inicial del texto fue leída en el I Coloquio de estudios de metafísica, organizado por el Grupo Origen UNMSM (Lima, 14 de noviembre de 2013). 


\section{Notas}

1 Dice Kant (2009) en la Introducción a la segunda edición de la Crítica de la razón pura (B 24) que se trata de "una ciencia indispensable para la razón humana, [ciencia] a la que se le puede cortar todo brote que le crezca, pero cuya raíz no se puede desarraigar".

2 Puede revisarse al respecto el libro IV, 2 de la Metafísica (Aristóteles, 1994), dedicado a la ontología y donde aparece la frase central del planteamiento aristotélico: "Ser se dice en varios sentidos".

3 El plan inicial de Ser y tiempo contemplaba dos partes, cada una en tres secciones (cfr. $\S 8$. El plan del tratado). Lo que se publicó en 1927 comprende solo las dos primeras secciones de la primera parte. Es decir, no se logró redactar la segunda parte, la destrucción de la historia de la ontología. Este hecho ha dado lugar a una discusión sobre el carácter inacabado de la obra.

\section{Referencias bibliográficas}

Albizu, E. (1989). Metafísica: anatema y clandestinidad. Arete, 1(1), pp. 5-14.

Aristóteles. (1994). Metafísica, introducción, traducción y notas de Tomás Calvo Martínez. Madrid, España: Gredos.

Conee, E. y Sider, T. (2013). Acertijos de la existencia. Un paseo guiado por la metafisica. Madrid, España: Alianza Editorial.

Garrett, B. (2010). Qué es eso llamado metafísica. Madrid, España: Alianza Editorial.

Gómez-Lobo, A. (Trad.). (2000). El Poema de Parménides, texto griego, traducción y comentario. Santiago de Chile, Chile: Editorial Universitaria.

Gramsci, A. (1970). Introducción a la filosofía de la praxis, selección y traducción de J. Solé-Tura. Barcelona, España: Península.

Grondin, J. (2011). Introducción a la metafísica. Barcelona, España: Herder.

Hegel, G.W.F. (2011 [1812-1813]). Ciencia de la lógica, vol. I: La lógica objetiva. Introducción, traducción y notas de Félix Duque. Madrid, España: Abada Editores.

Heidegger, M. (1997 [1927]). Ser y tiempo, traducción de Jorge Eduardo Rivera. Santiago de Chile, Chile: Editorial Universitaria.

Kant, I. (2009 [1781, 1787]). Crítica de la razón pura, edición bilingüe, traducción, estudio preliminar y notas de Mario Caimi. Ciudad de México, México: FCE, UAM, UNAM.

Lyotard, J-F. (2012). ¿Por qué filosofar? Cuatro conferencias. Barcelona, España: Paidós.

Maestro Eckhart. (2011). El fruto de la nada y otros escritos, edición y traducción de Amador Vega Esquerra. Madrid, España: Alianza Editorial.

Platón. (2015). Parménides, traducción, prólogo y notas de Guillermo R. de Echandía. Madrid, España: Alianza Editorial.

Sartre, J-P. (2005 [1943]). El ser y la nada, traducción de Juan Valmar. Buenos Aires, Argentina: Losada. 